\title{
Expert System for Diagnosing Diseases Cocoa Using the Dempster Shafer Method
}

\author{
${ }^{1}$ Annafi 'Franz \\ Software Engineering Technology \\ State Agricultural Polytechnic \\ SamarindaAgricultural management \\ Samarinda, East Kalimantan \\ annafifranz@gmail.com
}

\author{
${ }^{2}$ Nurlaila \\ Software Engineering Technology \\ State Agricultural Polytechnic \\ SamarindaAgricultural management \\ Samarinda, East Kalimantan \\ bintang_saddam@yahoo.co.id
}

\author{
${ }^{3}$ Putri Yus Andayani \\ Samarinda Polytechnic State \\ Agricultural Engineering Technology \\ Software Agricultural management \\ Samarinda, East Kalimantan \\ putriyushandayani@gmail.com
}

\begin{abstract}
Indonesia occupies the third position of the Reviews largest cocoa producing country in the world, but the challenge faced is that the disease that attacks the cocoa plant causes only $60 \%$ of the cocoa production is exportworthy. The Dempster Shafer method can be used to diagnose types of diseases in cocoa plants. The system can be used by cocoa farmers in Indonesia to minimize the attack of cocoa plant diseases, so that yields can be abundant. This research was conducted at P4S work is human, Linking. As a research location for six months, from September 2018 to March 2019, it includes the data taking, analysis, develop the applications, implementation, and testing. Expert system diagnosis of cocoa plant diseases using the Dempster Shafer method makes it easy for users to know the symptoms and diseases of the cocoa plant so that it can be used in diagnosing cocoa plant diseases.
\end{abstract}

Keywords- Expert System, Cocoa Plant Disease, Dempster Shafer

\section{INTRODUCTION}

Indonesia ranked third largest cocoa producing country in the world, this shows that the cocoa plant is very suitable because it matches the existing climate. With its position as the world's third cocoa producer Indonesia has a workforce of 1.6 million cocoa farmers he said the farmer, (2012). Cocoa is very well developed in Indonesia because there are many Indonesian people who have a livelihood as farmers. But the challenge Indonesia is a disease affecting cocoa plants cause only $60 \%$ of cocoa production worth of exports Zamroni (2013). Because cocoa is a commodity that is very popular in Indonesia at this time, then the cocoa crop quality assurance through fertilizing and cocoa disease should always be done.

Diagnosing of the disease to the cocoa crop needs to be done as quickly and as accurately as possible, because the cocoa plant diseases can rapidly spread and attacks throughout the field.

Based on the description above, it is necessary to do research with the title "Expert System Diagnosis of Plant Diseases Cocoa Method Using Dempster Shafer Based WEB" in the hope it easier for consumers and cocoa farmers to know the type of disease that is attacking the cocoa plant is based on the symptoms of the disease and can produce solutions to handle the cocoa plants are diseased, so many cocoa plants were saved and can increase the production and quality of the cocoa plant.

The resulting conclusion is Dempster Shafer method has been successfully used to diagnose types of diseases in the cocoa plant. It is expected that with this system the cocoa farmers in Indonesia can minimize the cocoa plant diseases, so that the crop can be abundant.
The reason for choosing the method Dempster Shafer for the completion of complex simply by choosing the symptoms it will issue a diagnosis of diseases with certainty in the form of a percentage value.

Based on the description of the background has been described, can be formulated the problem, namely how to create a web-based expert system application using Dempster Shafer method for diagnosing diseases in cacao plants based on symptoms seen in cocoa plants?

The boundary problem in this study are as follows:

1. An expert system developed only for the cocoa plant disease diagnosis.

2. An expert system developed by Dempster Shafer method.

3. This expert system is developed based on web.

Interest in the preparation of this paper is to develop an expert system that can be used to diagnose a disease affecting cocoa plants by symptoms of the disease by actors and observers in the field of cocoa plants.

The benefits of this research are:

1. for Consumers

a. Add insight into the cocoa plant diseases.

b. Can know about cocoa plants both in consumption and not good in consumption

2. For Cocoa Farmers

a. Easing cocoa farmers to determine the types of cocoa plant disease that is attacking the cocoa plant is based on the symptoms of the disease.

b. With this application is expected to help the cultivation of cocoa in obtaining information about a disease affecting cocoa plants and to increase the production and quality

\section{LITERATURE REVIEW}

\section{A. Study of literature}

Some of the literature is used as a guide and reference in this thesis include:

1. The research that was done by Defitri (2017) entitled Expert System pod disease of cocoa plant (Theobroma cacao L.) with the percentage of attacks using PHP and MySQL with simple random sampling method, carried out in the village of Betung, Kumpeh Ilir subdistrict Muara Jambi regency. Samples were randomly selected plants in the cocoa plantations of people who had already done a breakdown by degrees keterawatan gardens. Observations were carried out for symptoms of fruit rot disease caused by a fungus Phytophora palmivora, then dikumpulkkan data by calculating the entire fruit healthy or sick in order to get the percentage of fruit rot disease caused by a fungus Phytophora palmivora on untreated garden is 
$60,4 \%$, which means the disease include severe attack for over half of infected cocoa pods. While the garden is done intensive care fruit rot disease means $7.32 \%$ mild disease.

2. Research conducted by Nurcahyo et al (2018) Experts called the system for sugarcane crop disease identification method based on Dempster Shafer WEB. This expert system make it easier to determine the appropriate type of disease with symptoms caused. This system makes the process of disease identification and diagnosis deduction is calculated by the method of Dempster Shafer memenggunakan fact symptoms of the user. Results of the calculations Dempster Shafer has a $88.89 \%$ accuracy rate with manual processes. The system is expected to provide more complete information and accurate information on diseases of sugarcane in order to minimize losses and increase the productivity of sugarcane.

3. Research conducted by Handy et al (2016), entitled Detection Expert System watermelon plant diseases using Dempster Shafer WEB-based methods using PHP and MySQL. Withthe progress of the expert system can be developed a system of diagnosis of disease using Dempster Shapher reasoning methods for diagnosis on watermelon plants through applications that may help farmers to diagnose diseases of watermelon plant. Diagnosis system using PHP and MySQL web applications that are accessible to farmers allow their information to detect disease in watermelon plants by providing knowledge about the symptoms experienced by the plants so farmers will get what disease attacked the watermelon crop.

4. Research conducted by Sari et al (2016) entitled Expert System Diagnosis of disease in rice plants using a method based on Dempster Shafer android. With the presence of a disease affecting rice crops unnoticed by farmers, and farmers often do not understand about the disease that attacks the rice plants so late in penangganan to diagnose symptoms that make rice production to decline. In this case the experts in the field of agriculture can diagnose the symptoms of paddy facing farmers who were hit by the disease. However, due to time constraints it is not possible to diagnose agriculture experts throughout the region who were attacked simultaneously in a short time. Android-based application is designed to help the expert to determine the disease as determined by a combination of symptoms that occur.

5. Research conducted by Eve (2015), entitled Diagnosis Expert System cocoa plant diseases using methods Fordward Chaining web based programming language and MySQL 6.0. Expert System Diagnosis of disease on cocoa plants using methods Fordward Chaining in Indragiri Hilir Plantation Office is a system that can provide information statements of several types and characteristics of diseases that interfere with the cocoa tree. So that it can provide convenience for farmers untu know how to diagnose diseases of the cocoa plant. In developing this system Fordward Chaining author uses the method. So for the data collection method writer using interviews, observation and questionnaires. The system used in the use of PHP programming language and MySQL 6.0.

\section{B. Artificial intelligence}

Artificial intelligence (Artifitical Intelligence) Artificial intelligence is intelligence that is written by humans into a system of technologies, managed and developed in a scientific context, the formation of a scientific entity existing intelligence.

The goal of artificial intelligence is to make computers more intelligent, understand intelligence, and make the engine more useful for humans. Artificial intelligence can help ease the workload of humans, for example in making decisions, finding information more accurately, or to make computers easier to use with a display that is easy to understand. The workings of artificial intelligence is to accept input, for processing and then to output in the form of a decision.

\section{Expert system}

Expert systems (expert systems) is a system that is trying to adopt human knowledge kekomputer designed to resolve problems like an expert.

According to Turban (2009), the expertise of specialists transferred to a computer. This knowledge is then stored in the computer. By the time the user runs the computer to obtain information, expert systems inquire the facts and can make reasoning (inference) and come to a conclusion. Then, the expert system provides an explanation (provide conclusions on the results of consultations that has been done before).

\section{Methods Dempster Shafer}

Dempster Shafer theory is representation, and propogasi combination of uncertainty, where this theory has some characteristics that are instutitif in accordance with the way of thinking of a master, but a strong mathematical basis. Dempster Shafer method first introduced by Dempster, who experimented with a range of uncertainty of the probability models as a single probability. Then in 1976 the Dempster Shafer theory publish in a book entitled Mathematical Theory of Evident (Desiani, 2006). In general the Dempster-Shafer theory written in an interval [Belief, plausibility]. Belief (Bel) is a measure of the strength of evidence in support of a set of propositions. If the value is 0 (zero) it indicates that there is no evidence, and if the value of 1 indicates certainty.

$$
\operatorname{Bel}(\mathrm{X})=\sum_{\mathrm{Y} C \mathrm{X}} \mathrm{m}(\mathrm{Y})
$$

And plausibility is denoted in the equation:

$$
\text { Pis }(X)=1-\operatorname{Bel}(X)=1-\sum_{Y C X}^{n} m(X)
$$

Where:

$$
\begin{aligned}
& \text { Bel }(X)=\text { Belief }(X) \\
& \text { Pls }(X)=\text { plausibility }(X) \\
& m(X)=\text { mass function of }(X) \\
& m(Y)=\text { mass function of }(Y)
\end{aligned}
$$

Dempster-Shafer theory stating their frame of discrement denoted by the symbol $(\Theta)$. frame of 
discrement is the universe of discourse of a set of hypotheses.

so often referred to by the environment, namely:

$\Theta=\{\theta 1, \theta 2, \ldots \theta \mathrm{N}\}$

Where:

$\Theta=$ frame of discrement or environment

$\Theta 1, \theta N=$ element / elements inside environment

environmentcontains elements that describe the possibility as an answer, and the only one that will be in accordance with the answers you need. This possibility in Dempster-Shafer theory is called the power set and is denoted by $P(\Theta)$, every element in the power set interval has a value between 0 and 1 .

$m: P(\Theta)[0,1]$

So it can be formulated:

by:

$$
\sum_{X e P(\theta)} m(X)=1
$$

$P(\Theta)=$ power set

$m(X)=$ mass function $(X)$

Mass function(M) the Dempster-Shafer theory is the confidence level of an evidence (symptoms), often referred to as evidence that the measure is denoted by (m). The goal is to link elements of the confidence measure $\theta$. Not all direct evidence to support each element. For that we need the probability density function (m). Value'm not only defining the elements of $\theta$, but also all subsetnya. So if $\theta$ contains $n$ elements, then the subset $\theta$ is $2 \mathrm{n}$. The sum of all $\mathrm{m}$ in a subset of $\theta$ equals 1 . In the absence of any information to select the hypothesis, then the value of: $\mathrm{m}\{\theta\}=0.1$

If the unknown $\mathrm{X}$ is a subset of $\theta$, with $\mathrm{m} 1$ as a function of its density, and $Y$ is also a subset of $\theta$ by $\mathrm{m} 2$ as a function of its density, it can be formed functions as a combination of $\mathrm{m} 1$ and $\mathrm{m} 2 \mathrm{~m} 3$.

The formula of the theory Dempster Shafer:

Where:

$$
m 3(Z)=\frac{\sum x \cap Y=z m 1(X) \cdot m 2(Y)}{1-\sum x \cap Y=\theta m 1(X) \cdot m 2(Y)}
$$

$m 1=$ density of the first symptoms

The second symptom $m 2$ = density

$m 3=$ the combination of both the density of the above

$\theta=$ Universe of discourse of a set of hypotheses ( $X$ 'and

$\left.Y^{\prime}\right)$

$X$ dan $Y=$ subset dari $Z$

$X$ 'and $Y^{\prime}=$ Subset of $\theta$

\section{E. My database Structured Query Language}

According Kustiyahningsih (2011), "My Structured Query Language (MySQL) is a database that contains one or a number of tables. The table consists of a number of rows and each row contains one or several tables. The table consists of a number of rows and each row contains one or a number of tables ".

\section{F. Hypertext Preprocessor (PHP)}

According Kustiyaningsih (2011), "PHP (or official PHP: Hypertext Preprocessor) is a server-side scripts are written in HTML". In principle, the server will work if there is a request from the client. In this case the client uses the codes Hypertext Preprocessor (PHP) to submit a request to the server. Working system of Hypertext Preprocessor (PHP) begins with a request that beasal of web pages by the browser.

\section{G. Data Flow Diagram (DFD)}

Data Flow Diagrams (DFD) is a diagram notations used to describe the system data flow logic. DFD describes the components of a system.

\section{H. Flowchart (Flowchart)}

Flow chartis a schematic representation of a system that describes the physical relationships between entities (Subhan, 2012). Flowchart can be used to present the manual activity, the activity of computer processing or both.

\section{Entity Relationship Diagram (ERD)}

Entity Relationship Diagram (ERD) is a set of means or tools to describe the data or objects created by and derived from the so-called real world entities (entities) and relationships (relationship) between these entities using some notation. (Doro \& Stevalin).

ERD (Entity Relationship Diagram) is a model of approaches which states or describes the relationship of a model. In this connection it is stated that the main object is to show the data ERD (Entity) and relationships (Relationship), which is on the next Entity.

\section{J. Black Box Testing}

Black box testingis testing done only observe the execution results through the test data and the functional check of the software. So the analogy as we see a black box, we can see only the outward appearance, without know what's behind her black wrap. Just like the black box testing, evaluating only its external appearance (its interface), fungsionalitasnya.tanpa figure out what really happened in the process of the details (just knowing the input and output).

\section{K. Cocoa Plant Overview}

Cocoa plant (Theobroma cacao L.) is one of plantation crops dikembang expand in order to increase the country's foreign exchange resources of the non-oil sector. The cocoa plant is a member of the genus Theobrama of familia Sterculaieeae are widely cultivated, is systematically having taxa sequence as follows:

Division : Spermatophyta

Subdivisio: Angiospermae

Class: Dicotyledoneae

Order: malvales

Family: Sterculiaceae

Genus: Theobroma

Species: Theobroma cacao L.

Cacao (Theobroma cacao) is a tangible plant trees originating from South America. The plant seeds produced from refined product known as chocolate.Cocoa Plant DiseasesCocoa is an annual plant (perennial) in the form of trees, nature can reach a height of $10 \mathrm{~m}$. Nevertheless, the high cultivation was made not more than $5 \mathrm{~m}$ but with a canopy that extends sideways.

One way to diagnose a disease need to know first the symptoms were caused. Although only on clinical symptoms (symptoms that are seen directly or felt by the patient), the doctor can take a conclusion in the form of the illness. But 
there are times when further examination is required memalui laboratory tests for certain diseases.

Several types of disease is now often the case to the cocoa crop in Indonesia, namely:

1. Fruit rot disease (Phytophtora palmivora)

2. Cancer Stem (Phytophtora palmivora)

3. Vascular Streak Disease dieback

(VSD) (Oncobasidium theobromae)

4. Colletotrichum diseases (Colletotrichum gloeosporioides)

5. Fungus diseases Upas (Corticlum salmonicolor)

\section{RESEARCH METHODS}

\section{A. Place and time of research}

This study will be conducted in P4S WORKS INSANI Road Works Insani RT. 31 Berambai. as the place to be investigated. This study takes as long as 6 months of the month September 2018 - March 2019 includes the proposal, data collection, application development, and preparation of reports.

\section{B. Tools and Materials}

This information system development using a unit laptop with the following specifications.

Hardware specifications used in the development of this system are as follows:

1. ASUS laptop X453S

2. processor

Intel (R) Celeron (R) Dual-Core Processor N3050

Intel (R) Quad-Core Processor N3700

3. Operating system

Windows 10 Home

4. chipset

Integrated Intel (R) CPU

5. memory

DDR3L SDRAM at $1600 \mathrm{MHz} 8 \mathrm{~GB}$

6. Display

Auto HD (1366x768)

7. storage

2.5 SATA3 (500 GB HDD 5400 RPM)

8. Optical drive

Super-Multi DVD

9. card Reader

10. VGA Web Camera

Softtware specifications used are as follows:

1. Operating Systems Windows 10 Home

2. XAMPP

3. PHP WEB MyAdmin

4. Sublime Text

5. balsamic

6. Microsoft Visio

The materials used in the study is the Expert System: Data cocoa plant diseases and symptoms.

\section{Research procedure}

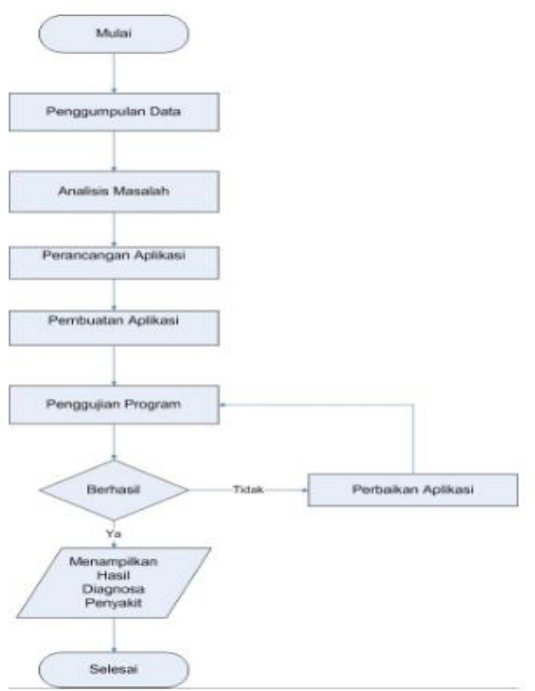

Picture 1, Research Procedure Diagram

\section{Analysis System Design}

In the depiction of the system design used is a flowchart diagram of the system, Context Diagram, Data Flow Diagrams (DFD).

Flow chart is a chart with specific symbols that describe in detail the process sequence and the relationship between an (instruction) with other processes in a program following 6 images flow system.

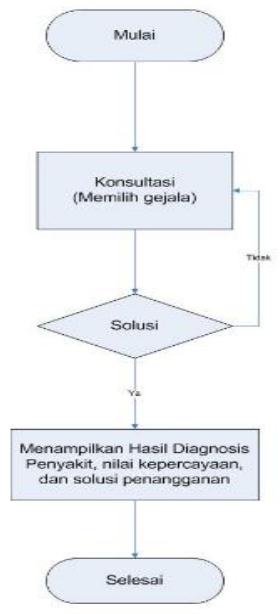

Picture 2, Flowchart Diagram System

DFD level 0 consists of two (2) entity that is an expert (admin) and user. Admin provides input to the system in the form of a data name of the disease, symptoms and information about the disease and ways to overcome them. Users register and then perform disease diagnosis by selecting the symptoms are attacked on the plant to the system and then the system provides the appropriate diagnosis. 


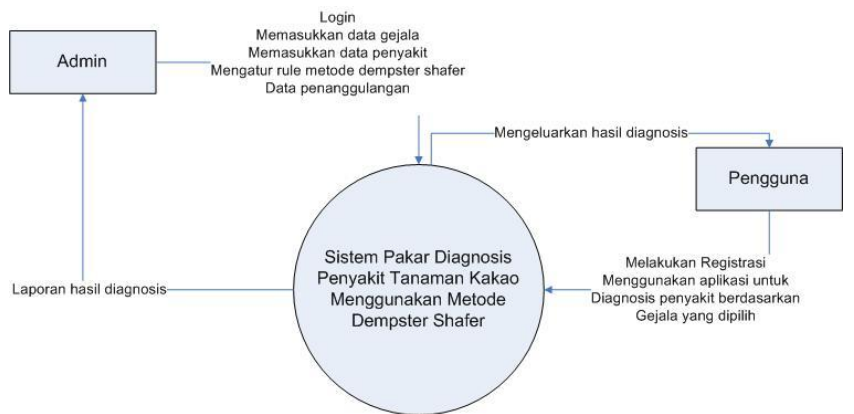

Picture 3, Context Diagram / DFD level 0

DFD level 1 consists of a single process, namely the identification of the initial fact, the process of identification, symptoms related and inference process. In Figure 16, the DFD level 1 there are 7 process for the first user to register and consult, then the admin the first login, the second data input process of symptoms, the third data input of diseases and solutions, and the fourth set of data rules and the consultation users ,

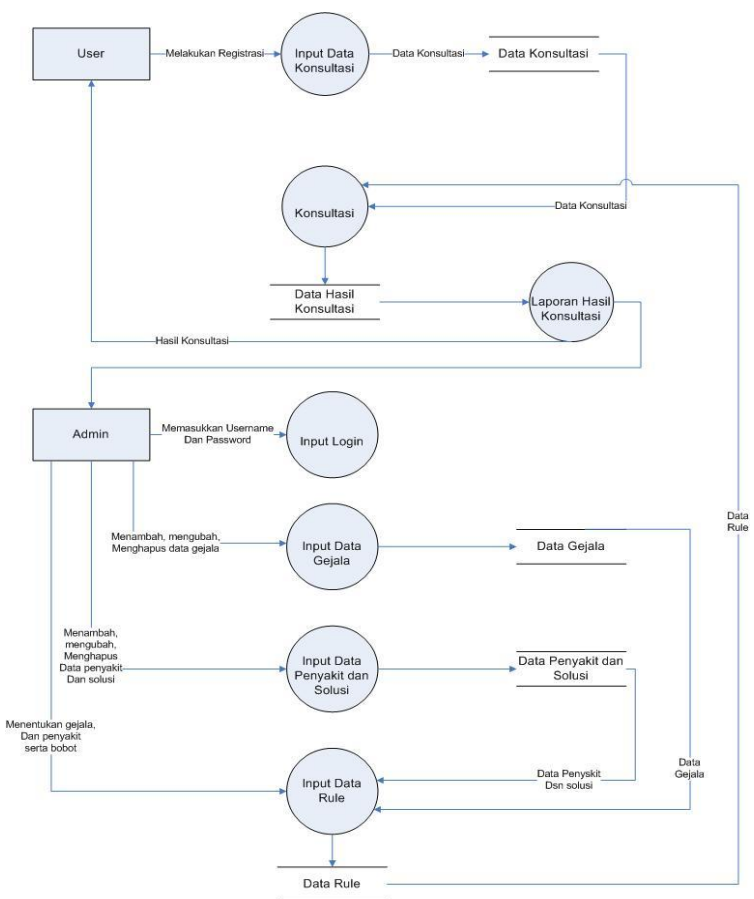

Picture 4, DFD level 1

ERD is used to describe the inter-entity berelasinya, In Figure 18 below is ERDPlant Disease Diagnosis Expert System Cocoa Dempster Shafer Based Method Using WEB this. Where there are 4 entities that includes user, Disease, Symptoms, Hasil_Konsultasi.

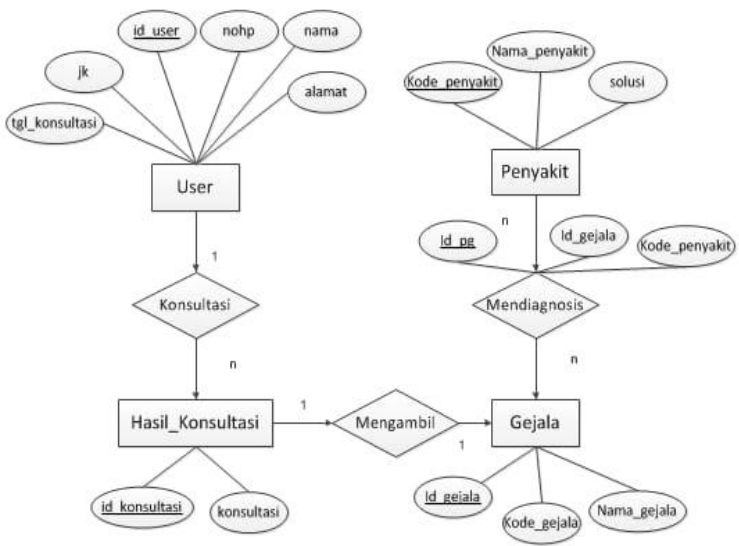

Picture 5, Entitty relaionship Diagram (ERD)

\section{E. Dempster Shafer Calculation Method}

Manual calculation using Dempster-Shafer method serves to provide an overview of the system to be built. The calculation process manualisasi Dempster-Shafer method, there are several steps. Example manualisasi will be on for three cases, namely the case 1 with the first calculation of symptoms, case 2 with the calculation 2 symptoms, case 3 with the calculation of three symptoms, the case 4 with calculation 45 cases with symptoms and 5 symptom calculation.

> Case 1 (1 Symptoms)

In this case will be exemplified by entering the first symptoms. These calculations incorporate user portion of fruit rot symptoms.

- Symptom 1: Rotten fruit portion

Fruit rot observations partly as a symptom of a disease with a value of $\mathrm{m} 1\{\mathrm{P} 01\}=0.7$, then:

$$
\begin{aligned}
& \quad \sum_{x \in P(\theta)} m(X)=1 \approx \sum_{x \in P(\theta)} m(X)=1 \\
& \mathrm{~m} 1\{\mathrm{P} 01\}=0.7 \\
& \mathrm{~m} 1\{\Theta\}=1-0.7=0.3
\end{aligned}
$$

- Symptom 2: Edge brown fruit

Observations brown end of the fruit as a symptom of the disease to the value $\mathrm{m} 2\{\mathrm{P} 01\}=0.6$, then:

$$
\begin{aligned}
& \mathrm{m} 2\{\mathrm{P} 01\}=0.6 \\
& \mathrm{~m} 1\{\Theta\}=1-0.6=0.4
\end{aligned}
$$

Next, calculate the new dentitas for some combinations (m3). Can be seen in Table 1 .

$$
m 1 \oplus m 2(Z)=\sum_{x \rightarrow \pi=Z} m 1(X) m 2(Y)
$$

Table 1. Combination Rules For m3

\begin{tabular}{|l|l|l|}
\hline \multirow{2}{*}{$\mathrm{m} 1$} & $\mathrm{~m} 2$ \\
\cline { 2 - 3 } & $\{\mathrm{P} 01\}=0.6$ & $\{\Theta\}=0.4$ \\
\hline$\{\mathrm{P} 01\}=0.7$ & $\{\mathrm{P} 01\}=0: 42$ & $\{\mathrm{P} 01\}=0: 28$ \\
\hline$\{\Theta\}=0.3$ & $\{\mathrm{P} 01\}=0: 18$ & $\{\Theta\}=0: 12$ \\
\hline
\end{tabular}

So it can be calculated:

$$
\begin{gathered}
m 1 \oplus m 2(Z)=\frac{\sum_{x \rightarrow Y-Z} m 1(X) m 2(Y)}{1-k} \\
m 3\{P 01\}=\frac{0.28+0.18+0.28}{1-0}=0.88 \\
m 3\{\Theta\}=\frac{0.18}{1-0}=0.18
\end{gathered}
$$


- Symptom 2: Fruit colored black

Observation carried black-colored fruit as a symptom of a disease with a value $\mathrm{m} 4\{\mathrm{P} 01\}=0.4$, then:

$$
\begin{aligned}
& \mathrm{m} 4\{\mathrm{P} 01\}=0.4 \\
& \mathrm{~m} 4\{\Theta\}=1-0.4=0.6
\end{aligned}
$$

Next, calculate the new dentitas for some combinations (m5).

Can be seen in Table 2.

Table 2. Rules For the combination between $\mathrm{m} 5$

\begin{tabular}{|l|l|l|}
\hline \multirow{2}{*}{$\mathrm{m} 3$} & $\mathrm{~m} 4$ & \\
\cline { 2 - 3 } & $\{\mathrm{P} 01\}=0.4$ & $\{\Theta\}=0.6$ \\
\hline$\{\mathrm{P} 01\}=0.88$ & $\{\mathrm{P} 01\}=0352$ & $\{\mathrm{P} 01\}=0528$ \\
\hline$\{\mathrm{P} 01\}=0: 12$ & $\{\mathrm{P} 01\}=0048$ & $\{\Theta\}=0.072$ \\
\hline
\end{tabular}

So it can be calculated:

$$
\begin{aligned}
& m 5\{P 01\}=\frac{0.352+0.048+0.528}{1-0}=0.928 \\
& m 5\{\Theta\}=\frac{0.072}{1-0}=0.072
\end{aligned}
$$

- Symptom 3: The fruit is mushy and wet

Observations fruit mushy and wet as a symptom of a disease with a value $\mathrm{m} 6\{\mathrm{P} 01\}=0.5$, then:

$$
\begin{aligned}
& \operatorname{m6}\{\mathrm{P} 01\}=0.5 \\
& \mathrm{~m} 6\{\Theta\}=1-0.5=0.5
\end{aligned}
$$

Next, calculate the new dentitas for some combinations (m7). Can be seen in Table 3.

Table 3. Combination Rules For m7

\begin{tabular}{|l|l|l|}
\hline \multirow{2}{*}{$\mathrm{m} 5$} & $\mathrm{~m} 6$ \\
\cline { 2 - 3 } & $\{\mathrm{P} 01\}=0.5$ & $\{\Theta\}=0.5$ \\
\hline$\{\mathrm{P} 01\}=0928$ & $\{\mathrm{P} 01\}=0.464$ & $\{\mathrm{P} 01\}=0.464$ \\
\hline$\{\mathrm{P} 01\}=0.072$ & $\{\mathrm{P} 01\}=0.036$ & $\{\Theta\}=0.036$ \\
\hline
\end{tabular}

So it can be calculated:

$$
\begin{aligned}
& m 7\{P 01\}=\frac{0.464+0.036+0.464}{1-0}=0.964 \\
& m 7\{\Theta\}=\frac{0.036}{1-0}=0.036
\end{aligned}
$$

- Symptom 4: Incurred a white coating such as flour

Observations raised the white layer like flour as a symptom of a disease with a value $\mathrm{m} 8\{\mathrm{P} 01\}=0.4$, then:

$$
\mathrm{m} 8\{\mathrm{P} 01\}=0.4
$$$$
\mathrm{m} 8\{\Theta\}=1-0.4=0.6
$$

Next, calculate the new dentitas for some combinations (m9). Can be seen in Table 4.

Table 4. Combination Rules For $\mathrm{m} 9$

\begin{tabular}{|l|l|l|}
\hline \multirow{2}{*}{$\mathrm{m} 7$} & $\mathrm{~m} 8$ & \\
\cline { 2 - 3 } & $\{\mathrm{P} 01\}=0.4$ & $\{\Theta\}=0.6$ \\
\hline$\{\mathrm{P} 01\}=0964$ & $\{\mathrm{P} 01\}=0.3856$ & $\{\mathrm{P} 01\}=0.5784$ \\
\hline$\{\mathrm{P} 01\}=0.036$ & $\{\mathrm{P} 01\}=0.0144$ & $\{\Theta\}=0.0216$ \\
\hline
\end{tabular}

So it can be calculated:

$$
\begin{aligned}
& m 9\{P 01\}=\frac{0.3856+0.5784+0.0144}{1-0}=0.9784 \\
& m 9\{\Theta\}=\frac{0.0216}{1-0}=0,0216
\end{aligned}
$$

From the results of the calculation method of Dempster Shafer, the highest density value was 0.9784 , $97.84 \%$ in the presentation can be summed disease affecting cocoa crop is fruit rot disease.
Manual calculations with the calculations of the value of the presentation of each disease application that was attacked had been appropriate.

\section{RESULTS AND DISCUSSION}

\section{A. result}

user interfaceis to see the outcome of the application. Here are some of the interfaces contained in the application, the following user and admin page views:

a.Tampilan user page consists of:

1. Main page

The main page is the initial appearance of the page the user when the user first enters this expert system application. The main page is shown in Figure 6.

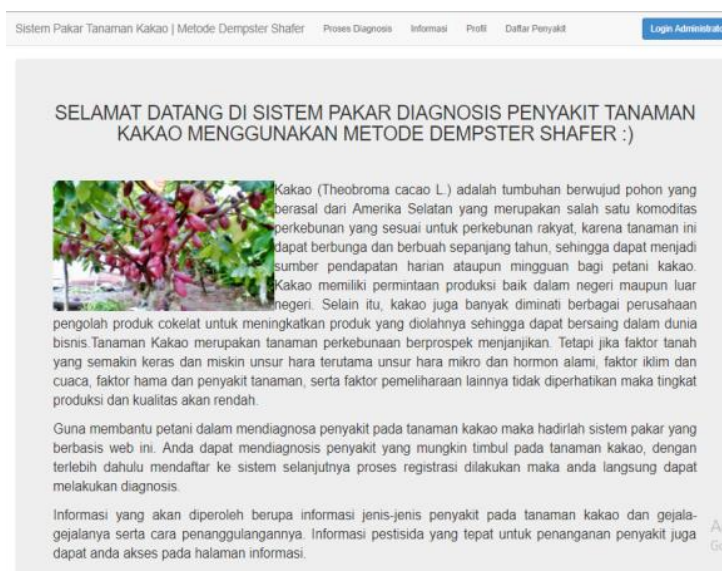

Picture 6, Main page

2. Maps profile

On the profile page described the maker profile application and how to use the application. The following profile view in Figure 7.

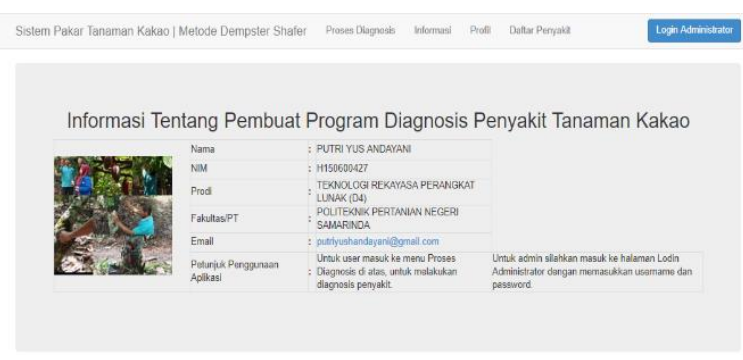

Picture 7, Maps profile

\section{Disease Diagnosis page}

Disease diagnosis page is a page that became a staple of the program for these pages the user through the diagnostic process so that the user knows the symptoms of the disease in each disease and know the disease experienced by the cocoa plant owned. Before making a diagnosis of the disease, the user required to register first to enter the yard diagnosis of the disease. Here's what the registration page can be seen in Figure 8. 


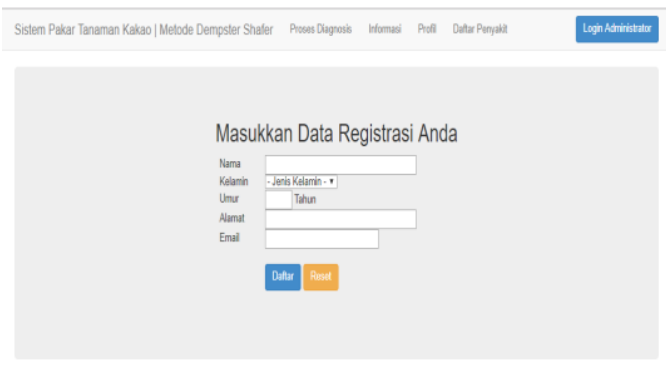

Picture 8, Registration page

After the user registration the user can be redirected to the next page in accordance with the diagnostic process has been registered. After that the user can mark the symptoms experienced by the cocoa crop as shown in Figure 9.

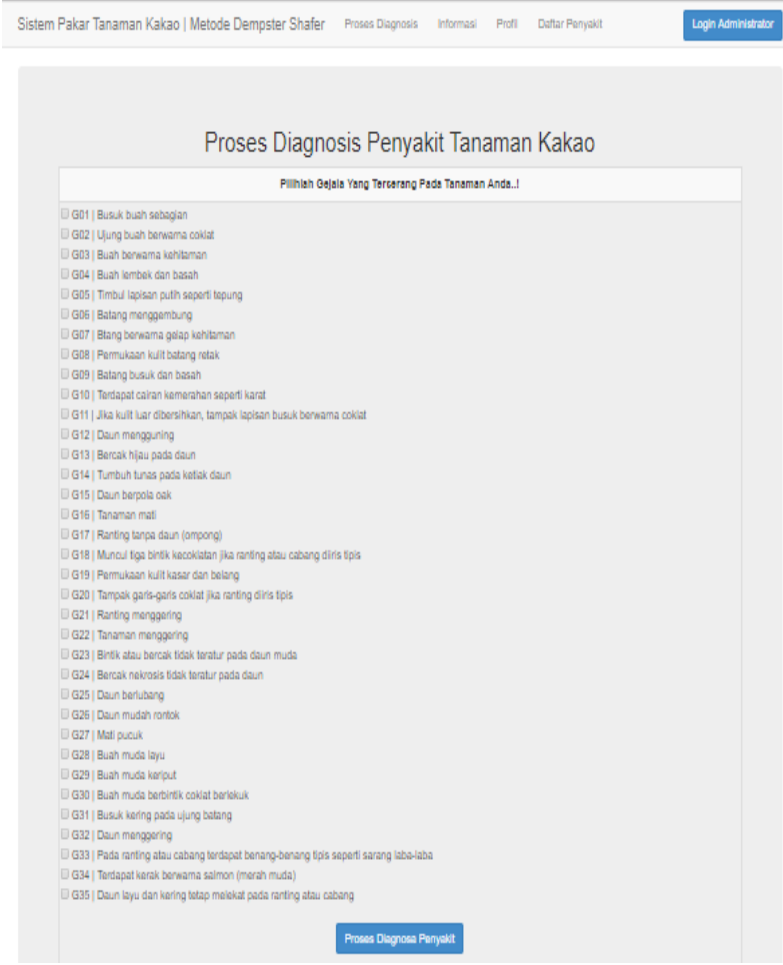

Picture 9, Diagnosis Process page

In the diagnostic process page, users who are marked gejalan selected it will exit the results display cocoa plant diseases with a confidence value and solutions penangganan existing diseases such as Figure 10 .

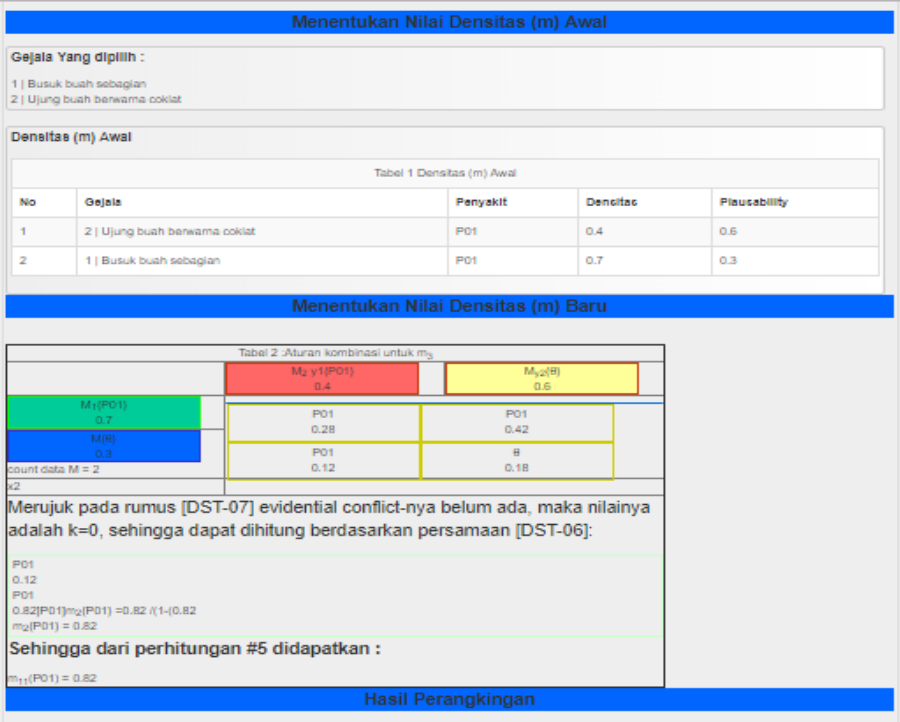

Dari hasil perhitungan yang terakhir tersebut kemudian diurutkan nilainya dari yang terbesar ke yang terkecil sebagai berikut :

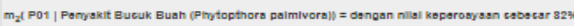

Pengendalian penyakit ini dapat dilakukan dengan cara melakukan sanitasi kebun, melakukan kultur teknis, atau juga dapat dengan cara menyemprotkan fungisida setiap 2 minggu sekali alau juga bišz

\section{Picture 10, Results Diagnosis Process}

a. Admin page views consist of:

1. Login page Expert

Login page views of experts, specialists can login by entering your username and password that have been registered as shown in Figure 11.

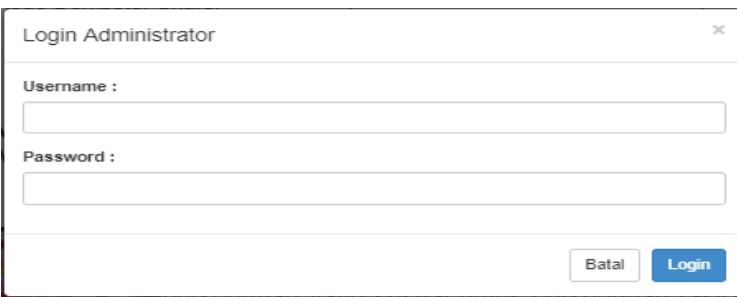

Picture 11, Login page Expert

\section{Expert Menu page}

Display expert menu page is different from the menu display to the user. On page expert menu consists of a menu of symptoms, diseases, rule, symptom reports and user reports. Here's what experts menu page can be seen in Figure 12.

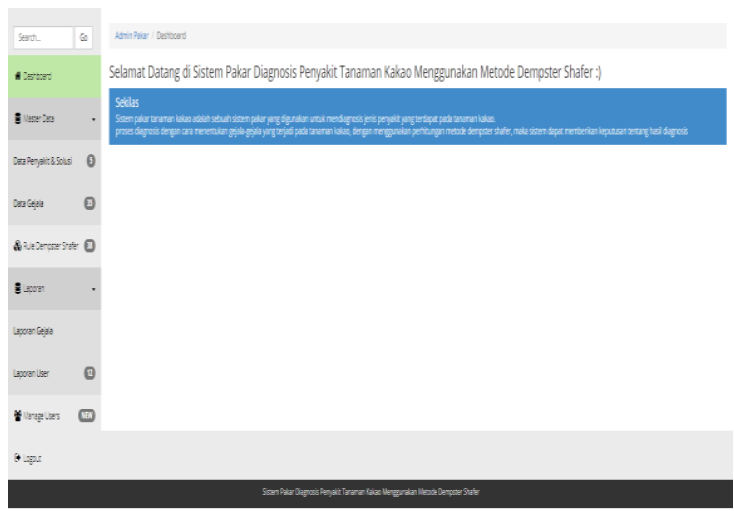

Picture 12, Tampilam Menu Specialists 


\section{Data page Symptoms}

Data page display symptoms of the expert can change the data on symptoms, symptom data add and delete data symptoms. The following symptom data page views in Figure 13.

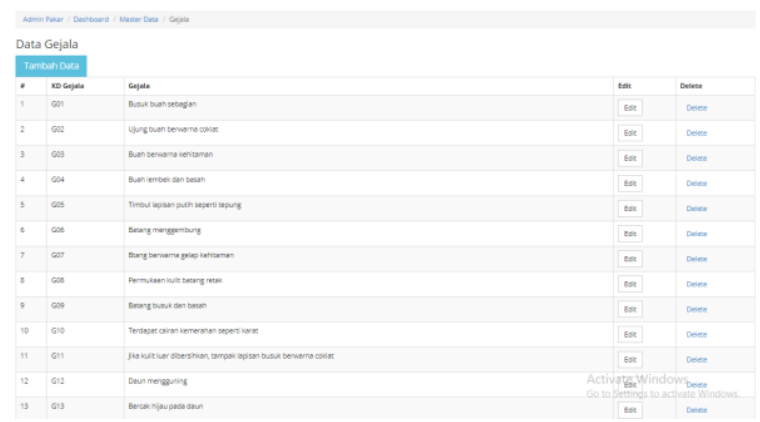

Picture 13, Data page Symptoms

\section{Weather Data Disease}

Data page display expert illness can change the data on the disease, adding to the disease data, and delete data illness. Here's what disease data in Figure 14.

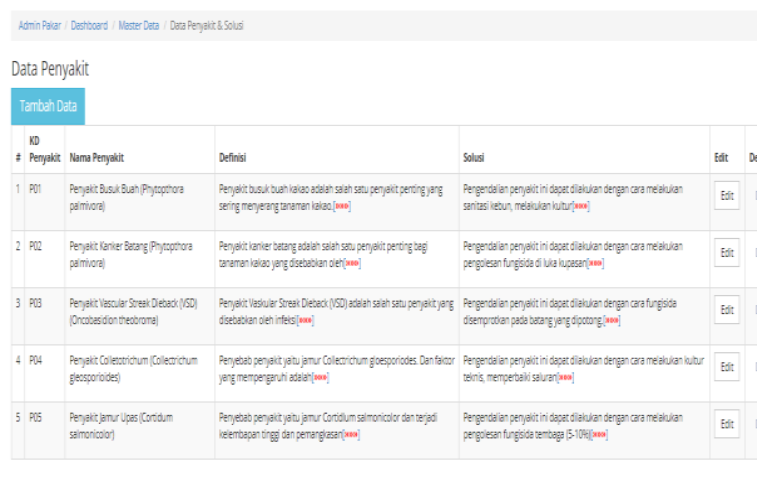

Picture 14, Page Disease

\section{Maps Relationships}

Views relations page contains code rule, and the value of belief given by experts. The following pages relation can be seen in Figure 15.

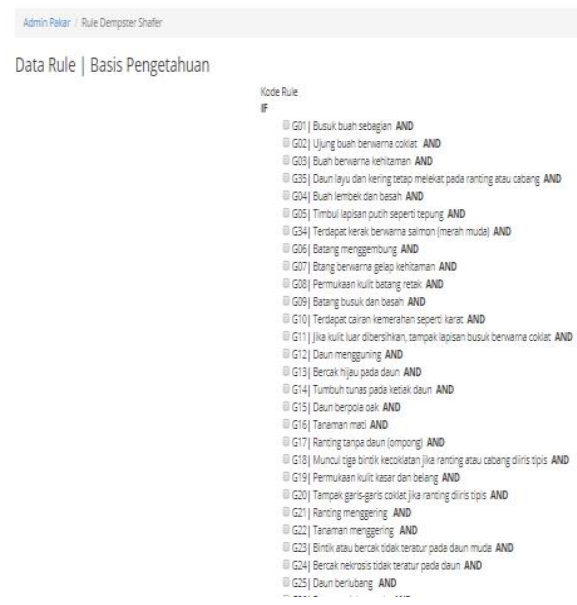

Picture 15, Maps Relationships
6. Weather Report Symptoms

Display page report contains data on each disease symptoms. The following pages report the symptoms can be seen in Figure 38.

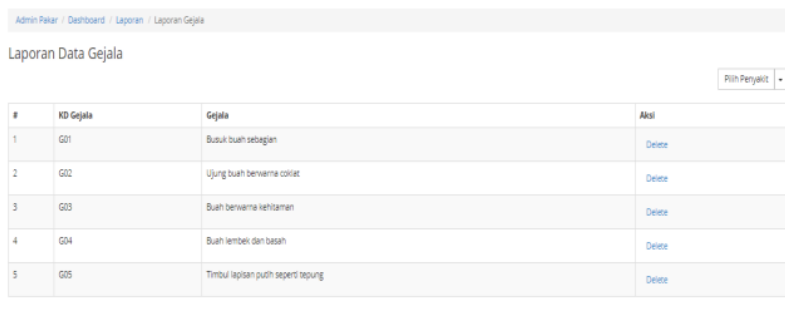

Picture 16, Weather Report Symptoms

\section{Weather Report User}

Page view user reports, experts can see which user data has been through the diagnostic process and the results of the diagnosis, disisni experts can only delete the data. Here the user reports page can be seen in Figure 39.

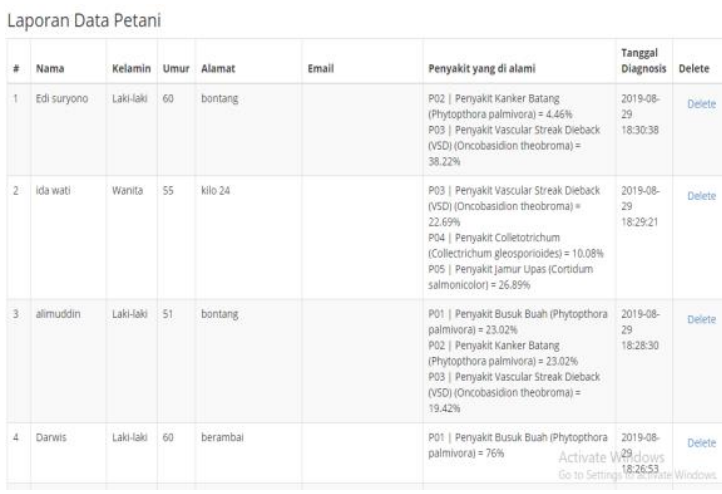

Picture 17, Weather Report User

\section{B. Discussion}

1. testing Systems

Testing disease diagnosis expert system application of cocoa plants using Dempster Shafer conducted to test the functionality of the application. Tests using black box method is used to demonstrate each function is fully operational as expected or not.

2. Validation testing

Validation testing is used for pushing determine whether the system created is correct as required.

\section{Questionnaire Results}

To measure the performance and benefits of the system then used a questionnaire. Testing in the form of a questionnaire consists of eight questions that were distributed to 30 respondents of different ages and occupations. Based on data from the results of the questionnaire, can be searched percentage of each answer using the formula $\mathrm{X}=\mathrm{P} / \mathrm{Q} * 100 \%$

6. Information:

7. $\mathrm{P}=$ Number of respondents answer each question 


\section{8. $\mathrm{Q}=$ Number of respondents \\ 9. $\mathrm{X}=$ Value Percentage}

\section{CONCLUSIONS AND RECOMMENDATIONS}

\section{A. Conclusion}

The conclusion of the expert system design and implementation of the cocoa plant disease diagnosis using Dempster Shafer web-based method is like this:

With the existence of this application allows users to know the symptoms and diseases of the cocoa plant so it can be used in making a diagnosis of plant diseases and methods Dempster Shafer cocoa can be used as an alternative in making the results of the determination of symptoms and diseases of cocoa plants.

\section{B. Suggestion}

For researchers will come to develop a system by using other methods.

To do further research to develop this system into a mobile based application so that its use can be widely used by many people to diagnose other diseases.

These applications can be developed into an application to diagnose other diseases.

[1] Arhami, M. (2005) Basic Concepts of Expert Systems. Yogyakarta. ANDI.
[2] Kusrini. (2008) Expert Systems Applications. Yogyakarta. Publisher Andi

[3] Yusa Safitri. (2017) Expert System pod disease of cocoa plant (Theobroma cacao L) with a percentage of attacks using PHP and MySQL, Jambi

[4] Joseph Nurcahyo. (2018) Expert System for identification of plant diseases cane with Dempster Shafer method using PHP and MySQL

[5] Mugirahayu H and Taufiq. (2016) Plant Disease Diagnosis Expert System Watermelon using Dempster Shafer Based Method WEB

[6] Eve. (2015) Plant Disease Diagnosis Expert System Using Cocoa Fordward chaining method using the web-based PHP MySQL version 6.0

[7] Arief, M. Rudyanto. (2011) Dynamic Web Programming using PHP and MySQL. Yogyakarta: Andi Publisher.

[8] Kustiyahningsih. (2011) WEB-Based Database Programming Using PHP and MySQL. Yogyakarta: Graha Science.

[9] Rahman, H. (2013). Design of Expert System Determines Cocoa Plant Disease-Based Method Using Forward Chaining WEB. Essay. Banda Aceh. Faculty of Engineering STIMIK U'budiyah Indonesia.

[10] Mustika Dewi Prihastuti. (2014). Application of Expert System For Early Detection and Treatment of the Cow Disease by DempsterShafer Method Based Web. Informatics Engineering. Faculty of Computer Science, University of Brawijaya, Malang.

[11] Maseleno, A. and Hasan, M. (2012). Avian Influenza (H5N1) using DempsterShafer Warning System Theory and Web Mapping. International Journal of Information and Communication Technology, Vol. 4, No. 2, 2012. ISSN. 1466-6422, pp. 227-141.

[12] Noviyanti. (2015). Plant Disease Identification System Soybeans Using Naive Bayes Method. Essay. Department of Computer Science, Faculty

[13] Beniyanto, A. (2011). Dempster - Shafer Theory. Bandung: Alfabeta 